\title{
(RE)PENSANDO TECNOLOGIA E RELIGIOSIDADE: TECNOGNOSE, JOGOS DE RPG E AMPLIAÇÃO DE CONSCIÊNCIA
}

\author{
(Re)Thinking Technology and Religiousness: Technognosis, RPGs and Conscience \\ Broadening
}

Rafael Justino da Silva Mestrando do PPG em Psicologia Clínica, UFPR rafael.justino.s@gmail.com

Carlos Augusto Serbena Professor Adjunto do Departamento de Psicologia da UFPR Doutor em Ciências Humanas UFSC caserbena@gmail.com

RESUMO: O artigo propõe que a tecnologia tem assumido expressões religiosas, das quais emergem os conceitos de tecnognose e tecno-religiosidade, fazendo referência a uma espécie de culto à tecnologia no qual aparecem fantasias de progresso e transcendência. Nesse contexto, os jogos digitais são vistos como um espaço de realização de algumas dessas fantasias, mas nota-se que não podem ser reduzidos apenas a isso. Nota-se que os jogos, em especial os de representação de papéis (RPGs), possibilitam a emergência de processos psicológicos paralelos à realização de fantasias que auxiliam no desenvolvimento da personalidade do jogador e na ampliação de sua consciência. Assim, defende-se que tecnologia e jogos digitais sejam considerados como objetos plurais, nos quais manifestam-se aspectos religiosos e fantasiosos bem como potenciais reais de desenvolvimento.

Palavras-chave: tecnologia; jogos; RPG; religião; consciência

ABSTRACT: The article proposes that technology has assumed religious expressions, from which emerge the concepts of technognosis and techno-religiousness, referring to a kind of cult to technology in which fantasies of progress and transcendence take place. In this context, videogames are seen as a place of fulfillment of some of these fantasies, although they cannot be reduced to just that. Parallel to the fulfillment of these fantasies, videogames, especially RPGs, allow the emergence of psychological processes that can help on the personality development of its players and the broadening of their conscience. Thus, we argue that both games and technology as a whole should be considered as plural objects, in which religious and fantastic aspects manifest along with real development potentials.

Keywords: technology; games; RPG; religion; conscience 


\section{Introdução}

Atualmente a religiosidade apresenta formas de expressão diversas, que distinguem-se em maior ou menor grau das liturgias de religiões institucionalizadas, como o cristianismo. Não se pode mais considerar como religiosas apenas as práticas e experiências que se passam dentro de igrejas, santuários, terreiros ou outros locais ditos religiosos. Ao longo dos anos, o tema ganhou a atenção de pesquisadores e pensadores de diferentes áreas do saber e os resultados de seus trabalhos compuseram um quadro misto de definições e formas de encarar os fenômenos e experiências relacionados à religião.

A variedade de novos grupos religiosos, igrejas, ensinamentos revolucionários e filosofias místicas que surgiram deixam nítida a heterogeneidade de práticas e rituais que se relacionam com o sagrado - aqui entendido como aquilo que se diferencia do considerado mundano e é qualitativamente diferente de uma experiência quotidiana (ELÍADE, 1992). Essa definição evidencia o aspecto idiossincrático e variável do sagrado, revelando uma gama ainda maior de objetos, técnicas e práticas que se relacionam a ele. Como afirma Elíade,

nas sociedades mais radicalmente secularizadas e entre os movimentos de juventude contemporâneos mais iconoclastas (...) existe uma série de fenômenos aparentemente não religiosos nos quais se podem decifrar novas e originais recuperações do sagrado. (...) significativas são as estruturas religiosas e os valores religiosos (...) da arte moderna, de alguns filmes importantes e extremamente populares, de uma série de fenômenos relacionados com a cultura dos jovens, (...) [como] a redescoberta da natureza, os costumes sexuais desinibidos, a ênfase dada ao 'viver no presente' e a ausência de 'projetos' e ambições sociais, etc. (1989, p.11)

Para ilustrar essas novas e originais recuperações do sagrado, podemos nos ater ao Jediísmo, a sétima religião mais popular no Reino Unido (COLLMAN, 2013). O movimento religioso tem suas raízes na mitologia do universo de Star Wars e seus membros acreditam na expressão e presença da Força, que como coloca o personagem do cavaleiro Jedi Obi-Wan Kenobi, "é um campo de energia criado por todos os seres vivos. Ela nos cerca e nos penetra. Ela mantém a galáxia como uma unidade." (CASTELlA, 2014). Como é explicado no site do Templo da Ordem Jedi, "Jedis 
verdadeiros não cultuam George Lucas ou Star Wars ou algo do tipo. Jediísmo não é baseado em ficção, mas aceitamos que o mito às vezes é uma forma mais prática de transmitir filosofias aplicáveis à vida real” (TEMPLE OF THE JEDI ORDER, s.d.). A filosofia Jedi é um misto coerente de certos aspectos do Taoísmo, Budismo, Catolicismo e do código Samurai, dando grande apreço a valores como humildade, coragem, lealdade, respeito e equilíbrio. Ao encararem o mito do filme como metáfora, os Jediístas veem além de sabres de luz e truques mentais e podem incorporar às suas vidas os princípios de conduta e modelos de relação com o mundo que se encontram subjacentes à narrativa mítica de Star Wars.

Com o exemplo, pode-se ver com mais clareza como um filme ou outras produções tecnológicas podem carregar elementos ou estruturas religiosas, como o mito, e servir como meio de contato com o sagrado. É pensando nisso que propomos as reflexões deste artigo. Em um primeiro momento, discutiremos como os mitos subjacentes à ciência e as fantasias ligadas às criações tecnológicas desempenham um papel importante na relação estabelecidada com o sagrado, dando forma a uma espécie de tecno-religiosidade ou tecnognose. Em seguida, discutiremos como os jogos digitais encaixam-se nesse contexto e como as experiências com o RPG Online podem auxiliar no desenvolvimento psíquico de seus jogadores.

\section{Ciência moderna, mito e tecnognose}

Hoje, ciência e tecnologia assumem um lugar central na vida em sociedade, cercando-nos com uma variedade de aparelhos e dispositivos e apresentando novas e excitantes descobertas que carregam o potencial de mudar os rumos da humanidade. Vale, então, refletirmos sobre o processo histórico-cultural que engendrou esse cenário e quais os mitos e fantasias que o compõem.

Antes do século XVII a mentalidade científica era significativamente diferente da atual. Para a ciência clássica, as regularidades observadas no mundo físico se dariam por qualidades inerentes aos objetos, como a tendência natural a permanecer em repouso estático, advindas de um princípio organizador que circundaria e atravessaria toda a existência. Tratava-se de uma postura contemplativa da natureza e de sua expressão e funcionamento, oposta à atual busca por seu desvelamento e controle. Na 
ciência clássica, o caráter principal da relação entre homem e natureza é o da experiência com ela, entendendo-a como parte de um todo - um cosmo - organizado e limitado, no qual os objetos possuem qualidades naturais e inerentes (KOYRÉ, 1986).

Os sistemas explicativos da ciência clássica encontraram seu limite com Galileu, que operou uma geometrização e matematização do mundo para que certas questões pudessem ser devidamente respondidas. Nesse momento, as ocorrências naturais poderiam ser explicadas numericamente, acreditando-se que a linguagem da natureza é a matemática (KOYRÉ, 1986). A matematização do mundo acompanhou o clima de enaltecimento da razão e da racionalidade presentes no Renascimento e nesse ponto, "o método [científico] não é mais uma submissão à natureza em se contentando em inferir classificações e taxonomias; ele tem a incumbência de submeter a natureza a si próprio, (...) de traduzi-la numa linguagem matemática muito mais operatória" (Miguel e Menardi apud LEMOS, 2004, p. 45). Enquanto a razão passa a ocupar lugar central na inteligibilidade do mundo, a técnica passa a ser o meio pelo qual dominá-lo e assim, o racionalismo toma o lugar do teocentrismo até então vigente.

Pela ascensão da razão, houve o declínio do imaginário, do mito, da religião e de tudo aquilo que a ela aparentemente se contrastava. Inaugurou-se a modernidade e com isso, imagens, crenças e sensações que se sedimentavam sobre experiências subjetivas, como a religião e a tradição, perderam seu valor em oposição ao peso esmagador da objetividade e do discurso racional e científico. A esse processo, o sociólogo Max Weber chamou de desencantamento do mundo (WEBER, 1920/2004).

A ciência moderna surgiu como possibilidade - e promessa - de desvelamento da realidade, capaz de traduzir os mistérios da natureza em formas e padrões racionais e inteligíveis. Ao incumbir-se da tarefa de explicar a realidade, a ciência assume um caráter mítico que antes pertencia a outros modos de explicação e orientação no mundo, como as religiões, tradições e mitos dos quais se diferencia (SIQUEIRA, 1999).

Assim, ironicamente formou-se ao redor da ciência uma espécie de culto, que glorifica os novos avanços científicos e adora as novas máquinas e dispositivos como arautos do progresso e da transformação social. As promessas e fantasias de progresso que acompanham ciência e tecnologia são hoje indissociáveis de nossa cultura e subjetividade. Dessa forma, há aqueles que fazem menção a uma "tecnocultura" (FELINTO, 2002), na qual podemos ver com frequência o surgimento de imagens que 
aludem à superação de coerções orgânicas, espaciais e temporais, como nos filmes da série Matrix ou no mais recente Interestelar. Os jogos digitais, especialmente os do gênero RPG, também se constituem como ricas fontes dessas imagens, uma vez que permitem ao jogador vivenciar um personagem com poderes sobre-humanos em um universo completamente distinto do dito "mundo real".

Portanto, apesar de serem pedras angulares do desencantamento weberiano, ciência e tecnologia já vieram ao mundo imbuídas de um caráter mitológico e até religioso desde seu nascedouro. Embora seja inegável que uma camada de fantasia revista as tecnologias, também é preciso reconhecer que algumas delas possibilitaram, de fato, a superação de certas coerções espaciais e temporais ao permitirem que seus usuários se comuniquem em tempo real apesar de grandes distâncias, ou que o façam sem preocupar-se com variáveis temporais, graças ao uso de inúmeros serviços de mensagens online, por exemplo. $\mathrm{O}$ corpo também assume lugar secundário em face às tecnologias, posto que agora podemos visualizar locais sem nunca termos estado lá fisicamente, assim como podemos ser transportados a mundos virtuais fantásticos sem sair de um cômodo, como acontece nos jogos de videogame.

Com a tecnologia, espaço, tempo e corpo assumem um lugar tangencial nas interações e com isso, modificam-se modos de relacionamento com o outro e consigo mesmo. Se antes as máquinas eram vistas como extensões do humano ao possibilitarem ações que o corpo não poderia desempenhar por si só, hoje podemos encarar a tecnologia como parte constituinte de nós mesmos. Tornamo-nos híbridos, sujeitos que não podem mais ser pensados apartados da tecnologia que nos cerca e que nos permite romper com limitações corporais e espaço-temporais.

As recentes tecnologias, em especial a Internet, elevaram o virtual a um dos principais fatores de criação da realidade. Uma realidade agora virtualizada, na qual o espaço é secundário, o tempo é uma variável contornável e as dicotomias entre interno e externo, privado e público, e sujeito e objeto têm seus limites testados (LÉVY, 2011). Se antes encarávamos a tecnologia como extensão do corpo, agora devemos encará-la como uma extensão da mente (FELINTO, 2002), dado que a tecnologia, hoje, é um meio responsável por novas e importantes descobertas científicas, assim como possibilita a expressão e partilha de uma miríade de sentimentos, ideias, imagens e experiências de todos os tipos entre os indivíduos. 
Assumindo a função de extensão da mente, ao redor da tecnologia circulam duas fantasias relativas à consciência: uma fantasia de expansão, na qual a consciência pode misturar-se ao ciberespaço e navegar livremente por ele; e uma fantasia de construção, na qual a consciência pode criar e tomar novas formas, tendo uma espécie de poder divino (re)criador (FELINTO, 2002).

Agora, além de nos permitir o domínio da natureza, a tecnologia permite que rompamos - fantasiosamente ou não - com as coerções orgânicas e espaço-temporais que nos limitam, dando forma e força a imagens e fantasias de divinização do humano. É no seio dessas imagens que se gestou a ideia de tecnognose. O termo "gnose" aparece no início da era cristã, quando surgiram seitas sincréticas que aliavam alguns ideais cristãos a paganismo e neoplatonismo. Esses grupos eram genericamente chamados de gnósticos, pois partilhavam a crença de que tinham uma gnosis, um conhecimento secreto, capaz de conferir aos seus adeptos a salvação espiritual (FELINTO, 2004). Paralelamente, os gnósticos também partilhavam a ideia de que a matéria, especialmente o corpo material, deveria ser superada, uma vez que a verdadeira essência humana estaria aprisionada no corpo. Assim, há no gnosticismo a transposição de um divino exteriorizado, objetificado, para um divino interiorizado, uma "divinização do self", como coloca Felinto (2002, p. 17). O divino, portanto, não estaria apartado do sujeito, mas sim (preso) no sujeito.

Dessa forma, o gnosticismo expressa-se como uma forma de religiosidade "humanizada", na qual o caminho para o sagrado reside no cuidado e desenvolvimento do espírito através de técnicas variáveis - os conhecimentos secretos. Assim, podemos encarar a gnose como uma técnica do espírito, e tecnognose, portanto, como a tecnologia encarada como plataforma possibilitadora da realização de fantasias de superação e transcendência da matéria e da consciência, aproximando-nos do sagrado. A esse respeito, o filme Transcendence tem muito a dizer ao contar a história de uma consciência que ganha propriedades divinas ao ser transferida para um computador.

Dentro do contexto de enaltecimento da tecnologia e da atribuição de um caráter potencialmente transcendental a ela, gestou-se o conceito de tecno-religiosidade. $\mathrm{O}$ termo encontra-se próximo à tecnogose à medida em que ambos colocam na tecnologia as esperanças de salvação - do espírito, da sociedade, da democracia... - e tratam-na como sagrada. Além disso, a tecnologia ainda assume um caráter religioso mais literal, 
religando os indivíduos ao permitir a partilha de imagens e experiências em grande escala, criando um sentimento de pertencimento e coletividade, uma aura emocional compartilhada (MAFFESOLI, 2006). Quando se assiste a um programa de TV, como a um noticiário ou novela, compartilham-se as imagens e emoções conectadas a ele, fazendo-as serem vivenciadas coletivamente. Maffesoli mostra que

a televisão permite 'vibrar' em comum. Chora-se, ri-se, sapateia-se em uníssono, e assim, sem que se esteja realmente em presença dos outros, cria-se uma espécie de comunhão, cujos efeitos sociais ainda precisam ser mensurados (1995, p. 76).

Maffesoli é o defensor da ideia de reencantamento do mundo, oposto ao desencantamento weberiano. $\mathrm{O}$ mundo reencantado é o mundo onde as imagens, mitos e fantasias ganham poder novamente, e a racionalidade objetiva perde força para experiências mais ligadas a dimensões subjetivas, tornando insustentável a ideia de um homem exclusivamente racional. Em entrevista, o sociólogo francês diz que poderia ter alcunhado o termo como "remagificação" do mundo (YOUTUBE, 2015), em referência à volta não apenas do poder imagético, mas à presença mesmo que fantasmática da magia no pensamento humano contemporâneo, como pode-se ver na popularização da astrologia, filosofias da nova era, o retorno a tradições milenares, ou mesmo nas fantasias de desmaterialização e transcendência ligadas à tecnologia.

Nesse contexto, os jogos de videogame entram em cena. Além de terem uma expressiva presença de magia em seus mundos digitais, os jogos também podem proporcionar a vivência de fantasias tecnognósticas em alguma medida. As narrativas e, particularmente, os mitos que compõem os jogos também ganham relevo pela possibilidade de serem incorporados, contribuindo para a ampliação da consciência de seus jogadores e modificando a forma como relacionam-se com o mundo, como Star Wars fez aos jediístas.

O universo de jogos digitais é imenso, com diferentes gêneros de jogo, cada um com suas particularidades. Aqui, faremos o recorte de tratar sobre jogos do gênero de RPG - Jogo de Representação de Papéis, em português. Os jogos desse gênero, via de regra, apresentam ao jogador a oportunidade de representar o papel de um herói com a missão de salvar o mundo ou restabelecer o equilíbrio a ele ou a uma situação particular. Os RPGs também costumam ser jogos com enredos mais ricos, frequentemente construídos sobre uma mitologia criada especialmente para um jogo ou sua franquia. 
Assim, quando se joga RPG, o jogador transporta-se para um mundo diferente daquele no qual vive cotidianamente, assumindo o papel de um herói com poderes mágicos e importantes missões.

\section{O RPG Online e as fantasias tecnognósticas}

Diferente dos outros gêneros em que o jogador também assume papéis heroicos envolvidos em grandes feitos, como jogos de ação ou aventura, os RPGs investem principalmente no aspecto narrativo da experiência, aprofundando e enriquecendo o enredo do jogo e a história daquele mundo particular e de seus heróis. A liberdade que o jogador tem em relação ao(s) herói(s) que controla também é central nos RPGs: cabe a ele decidir rumos de seu desenvolvimento, escolhendo investir em uma ou outra habilidade, ter esse ou aquele equipamento, montar uma equipe de heróis com uns e não outros personagens, etc. Em alguns casos, os jogadores podem até influenciar o rumo da história de acordo com as decisões que tomam durante o jogo.

Embora filmes e livros também transportem seus espectadores e leitores para situações e dramas heroicos, eles o fazem colocando o sujeito em uma posição relativamente passiva. Apesar da imaginação criar cenas e dar vida à narrativa que se desenrola em um livro, seu leitor está inevitavelmente preso às ações pré-estabelecidas na história. Os videogames, ao contrário, permitem que seus jogadores atuem sobre os mundos em que se processam as narrativas com certos graus de liberdade. Assim, aqueles que se envolvem com um RPG não são apenas jogadores, mas atores em um determinado universo seguindo um roteiro parcialmente criativo e pessoal.

Graças aos desenvolvimentos tecnológicos e econômicos dos últimos anos, uma variação do RPG popularizou-se: o RPG Online, ou MMORPG ${ }^{1}$. Nele, são mantidas as características centrais do RPG, em especial a liberdade de desenvolvimento do herói, acrescidas da oportunidade de interação em tempo real com outros jogadores, que compartilham um mesmo universo de jogo simultaneamente. Trata-se de um gênero de jogo online, em que diversas pessoas ao redor do globo podem se encontrar enquanto exploram o mesmo mundo digital do qual fazem parte. Em geral, os jogos desse tipo fazem com que seja necessário cooperar com outros jogadores a partir de algum ponto

\footnotetext{
${ }^{1}$ Massive Multiplayer Online Role-Playing Game, ou Jogo de Representação de Papel Online para Múltiplos Jogadores
} 
da experiência a fim de alcançarem objetivos mais difíceis. Assim, montam-se equipes temporárias ou duradouras para matar monstros mais fortes e conseguir melhores equipamento e mais dinheiro, possibilitando o progresso no jogo.

A interatividade entre jogadores no MMORPG é uma característica que o diferencia ainda mais de outros gêneros de jogos digitais, nos quais o contato entre jogadores é comparativamente reduzido ou nulo. Além de formarem grandes e pequenos grupos, os jogadores podem conversar livremente entre si durante o jogo, estando próximos um do outro ou não. O mais popular dos MMORPGs contemporâneos chamase World of Warcraft, lançado em 2004 pela desenvolvedora Blizzard. Foram contabilizados um total de 100 milhões de usuários registrados desde seu lançamento até 2014 e atenta-se para o fato de que o número equivale à quantidade total de brasileiros com acesso à internet. Atualmente, o número de usuários no jogo encontra-se em torno dos 7 milhões (STATISTA, 2015), mas deve-se levar em consideração que o número é apenas representativo dos jogadores cadastrados em servidores oficiais do jogo, que são pagos. Há um grande número de servidores piratas e gratuitos do jogo nos quais não se contabilizam os jogadores.

No game, o jogador pode escolher entre 13 raças de heróis, que se dividem igualmente entre duas facções inimigas, e 11 classes ou "tipos" de heróis - bruxos, paladinos, sacerdotes, etc. Além das disputas de território entre elas, as duas facções também precisam lutar contra males maiores, que ameaçam o mundo de Azeroth. A mitologia do jogo é extremamente rica e seu enredo é apresentado através de textos frequentemente narrados, que somam seis milhões de palavras, o equivalente a 12 livros de "O senhor dos Anéis" (G1, 2014). Além das informações dentro do próprio jogo, também foram lançados contos, livros e histórias em quadrinhos que expandem e aprofundam sua mitologia e enredo.

O estudo de Smyth (2007) aponta que o MMORPG é um novo tipo de experiência para jogadores. Em sua pesquisa, grupos de jovens foram selecionados aleatoriamente para jogar diferentes tipos de jogos digitais durante um mês, em diferentes plataformas, como fliperamas, consoles e computadores. Apenas o grupo que jogou MMORPGs teve divergências significativas, apresentando mais horas de jogo, piora na saúde e na qualidade do sono e maior interferência em socializações da vida real e em suas tarefas acadêmicas. Ao mesmo tempo, o mesmo grupo também relatou 
maior prazer em jogar e interesse em continuar jogando, além de maior aquisição de novas amizades, resultado direto das possibilidades de interação apresentadas pelo jogo.

É importante notar que o estudo de dezesseis pesquisas acerca do uso de MMORPGs realizada por Sublette e Mullan (2012) mostra que apenas os jogadores considerados como "viciados" ou com "modo de jogar problemático" sofriam efeitos negativos significantes que resultavam do jogo, ao passo que a maioria dos jogadores relatavam aspectos positivos da experiência. As autoras também indicam que os jogos que mais consomem tempo e atenção dos jogadores são aqueles em que o elemento do RPG se encontra.

Se lembrarmos das fantasias de transcendência do corpo e de uma consciência criadora, veremos que o MMORPG é o espaço que mais concretamente permite a vivência dessas fantasias. Corpo e consciência encontram-se desterritorializados no game, com o jogador presente tanto no mundo fora do jogo como naquele dentro do jogo. Dependendo do grau de imersão do jogador, podemos até mesmo dizer com segurança que suas necessidades físicas assumem importância secundária durante a maior parte do tempo engajado na experiência. Além de transcender a prisão material e incorporar sua consciência em um objeto virtual, o jogador está presente em um outro mundo, mágico, misterioso, virtual e, acima de tudo, vivo, compartilhado e interativo. No jogo, até a morte é superada, uma vez que mesmo que o herói morra nas garras de monstros ou de outros jogadores, sua ressurreição é garantida.

O jogador também pode dar vasão à sua criatividade no jogo ao (re)criar-se como herói. O herói é a personificação do jogador no mundo virtual, e ao assumir o papel de intermediador entre um e outro, podemos encará-lo como a persona do jogador naquele ambiente. A persona é um segmento coletivo da psique, cuja função é intermediar a relação entre o sujeito e o mundo externo. Ela é "aquela parte da personalidade desenvolvida e usada em nossas interações, nossa face externa consciente, nossa máscara social" (HOPCKE, 2011, p. 100). Assim, o herói torna-se persona à medida em que intermedia a relação entre o jogador e o mundo virtual.

Nesse ponto, vale uma reflexão sobre a construção do herói-persona no RPG. Se no mundo fora do jogo temos alguma liberdade para nos reinventarmos nas interações que travamos, essa liberdade é exponenciada no mundo digital. Nele, diluem-se as coerções físicas e podemos escolher a aparência que desejarmos, bem como a forma 
como agiremos naquele ambiente. Trata-se de um processo de escolha bastante intencional, no qual o jogador torna-se criador de si mesmo. Isso abre possibilidades significativas de novos modos de relacionar-se com o mundo, uma vez que se um sujeito é reservado e cauteloso no mundo fora do jogo, pode assumir uma persona mais extrovertida e agressiva no mundo digital. Do ponto de vista psicológico, tal possibilidade é fecunda pois permite ao sujeito o contato com aspectos de sua personalidade que até o momento não foram explorados ou desenvolvidos, o que resulta em potenciais ampliações das possibilidades de ação do sujeito no mundo (dentro e fora do jogo) e na mudança de suas perspectivas sobre si e sobre o outro.

Ao dar vida e voz a um objeto imaterial que tem características próprias ao mesmo tempo em que é construído pelas características de seu criador, o jogador aproxima-se de uma posição divina, na qual torna-se um "demiurgo que produz não apenas novos mundos e seres, mas que também pode recriar-se indefinidamente" (FELINTO, 2002, p. 22). Sem dúvida, essa espécie de tela em branco que o RPG oferece abre portas à expressão de uma pluralidade de (novos) elementos da psique do jogador, aproximando-o do contato com o que Hillman (1988) chamou de politeísmo da psique.

Frequentemente o "corpo virtual" do jogador, que se manifesta pelo herói, é chamado de "avatar". A palavra, que vem do sânscrito, significa "descendente de uma entidade divina" (DAVIS, 2006, p. 333) e representa uma manifestação particularizada de um deus. Diferentes avatares de um mesmo deus podem ter características e personalidades distintas, revelando não se tratar apenas de uma espécie de disfarce usado pelo deus. Se um avatar é um descendente de deus que também carrega suas próprias características, podemos ver o herói no jogo como um descendente do próprio jogador, uma forma virtual intencionalmente construída por sua psique, poderosa e imortal.

Satisfazendo as fantasias (tecno)gnósticas presentes em nosso imaginário contemporâneo, não é difícil perceber de onde a atração do RPG retira parte de suas forças. Talvez por realizar algumas (ou muitas) de nossas fantasias, os jogos de videogame no geral comumente são associados a um escape da realidade. Se pensarmos o jogo como Huizinga (2000), veremos que de fato trata-se de uma suspensão temporária de uma realidade para que outra tome cena - o que, a propósito, alude ao 
ritual e ao sagrado. Contudo, essa suspensão de realidade não pode ser confundida com um escape à ela. Huizinga defende a ideia de que o jogo é uma totalidade, ou seja, tem seu sentido e finalidade próprias, que fogem a motivos racionais, como preparar-se para ou escapar dessa ou daquela atividade, embora possa fazê-lo em paralelo. O prazer, envolvimento e a excitação decorrentes do jogo desempenham papel muito mais preponderante do que qualquer outro de seus efeitos secundários e, em última instância, são entendidos como os motivadores do jogo.

Embora seja importante manter em mente que em alguns casos o jogo possa tornar-se uma atividade cuja função principal na vida de um indivíduo seja a de fuga de uma realidade penosa, é igualmente importante notar que esses casos costumam ligar-se a patologias como a dependência de internet ou de jogos eletrônicos (ABREU, KARAM, et al., 2008). Na normalidade das experiências com jogos, o desligamento da realidade é muito mais um resultado secundário da atividade do que sua finalidade ou motivação. Da mesma forma que se lê um livro ou vê-se um filme pelo interesse em seu conteúdo, joga-se um jogo pelos atrativos de sua experiência, não como apenas um meio de fugir da realidade. Encarar o jogo e pensa-lo como escape é um empobrecimento unilateral do fenômeno e distanciamo-nos dessa posição. Encaramo-lo como uma atividade intencional que assume formas e funções variadas e, mesmo que em meio a elas estejam a realização de certas fantasias, o jogo não é a elas reduzido. Os jogos tornam-se mais ricos quando vistos em sua totalidade e, especialmente, quando dá-se atenção às experiências que se processam dentro deles.

\section{Ampliação de consciência}

Além das fantasias de desmaterialização da consciência presentes na tecnoreligiosidade, também notamos a fantasia de expansão ou ampliação da consciência que as tecnologias da comunicação fomentam, em especial a Internet. Nessa fantasia, confunde-se ampliação de consciência com acúmulo de informações, que se encontram aos montes no ciberespaço e tratam dos mais variados assuntos. Ao circunscrevermos nossa análise ao MMORPG, não pensamos que a ampliação de consciência possa ser feita no jogo por algum acúmulo de informações disponíveis. Encaramos essa ampliação em função de três eixos principais: primeiro, pelo já mencionado possível contato com aspectos pouco desenvolvidos da personalidade do jogador que se 
manifestam em seu herói-persona; segundo, o encontro com a alteridade no jogo, manifesto nas interações e alianças que os jogadores vivenciam entre si; e terceiro, pela incorporação metafórica ou simbólica do mito subjacente ao jogo.

Quando nos envolvemos em um mito e tornamo-nos seus atores, podemos experimentar a vida miticamente e abrimo-nos para captar seu aspecto metafórico, suas lições e modelos de relação com o mundo. Isso significa dizer que "podemos enxergar nossas vidas quotidianas tanto encaixadas na vida dramática e cosmogônica das figuras míticas quando enobrecidas por ela" (HILLMAN, 1988, p. 45). O mito incorporado confere uma mudança de perspectiva e sensibilidade do sujeito frente às configurações que permeiam seu estilo de vida e pensamento, o que por sua vez, tende a alterar em alguma forma a maneira com que lida com nosso entorno. Para Hillman (1988), são nessas mudanças de perspectiva que nos encontramos com o sagrado.

Nesta última seção, faremos uso de algumas falas de jogadores de World of Warcraft (WoW) para ilustrarmos alguns dos efeitos do MMORPG sobre a consciência dos jogadores. As falas foram retiradas de uma pesquisa piloto online disponibilizada para jogadores de WoW em redes sociais e fóruns sobre o jogo. Não houve quaisquer restrições à participação na pesquisa e alcançou-se o total de 319 respondentes. A idade média dos participantes é de 21 anos, com aguda distribuição entre gêneros, com $80 \%$ dos participantes de sexo masculino e $20 \%$, feminino. A pesquisa piloto almejava um quadro panorâmico a respeito de algumas experiências com o jogo e continha perguntas acerca de aprendizados nele. Em uma, os jogadores poderiam apenas concordar ou discordar da afirmação de terem aprendido algo que consideravam útil às suas vidas com o jogo. Outra pergunta permitia que eles escrevessem livremente sobre o que aprenderam, sendo a fonte dos excertos utilizados. Sobre a recém-comentada observação de Hillman à respeito da descoberta do sagrado na mudança de perspectivas, ilustramos:

Aprendi que devemos ser como os druidas ${ }^{2}$, ter respeito à vida e à natureza, que acima de tudo devemos zelar pela sobrevivência do nosso mundo e dos que vivem nele, lutando juntos contra um 'mau maior (Júlio, 18 anos)

Aprendi que cada um tem uma função importante na vida (Luan, 27 anos)

\footnotetext{
${ }^{2}$ Druídas são uma classe de heróis em WoW que "controlam os vastos poderes da natureza para preservar o equilíbrio e proteger a vida.” (WORLD OF WARCRAFT, 2015)
} 
Vemos nesses casos que tanto as dimensões mitológicas quanto práticas ou mecânicas do jogo podem ser incorporadas à consciência dos sujeitos. A fala de Luan provavelmente faz menção a horizontalidade presente no jogo: as diferentes classes ou "tipos" de heróis são todas igualmente importantes na composição de estratégias, além de haver um forte componente de interdependência nas batalhas que uma equipe trava.

A mitologia de WoW e outras informações de pano de fundo a respeito de seu universo é conhecida como "Lore". A caracterização de raças, classes, conflitos do jogo, etc. compõem a Lore e são disponibilizadas online, dentro do próprio jogo e também em livros, que expandem e aprofundam o enredo e o pano de fundo do jogo. Podemos notar que a Lore dá acesso a informações e narrativas que podem servir ao propósito de alterar em alguma medida perspectivas e posturas frente à vida e ao ambiente. Trata-se da incorporação de uma lição metafórica - ou não - dos mitos fundantes do jogo.

Depois de conhecer a história e ler os livros, gostei muito do equilíbrio que os pandarens ${ }^{3}$ presam. Às vezes lembro disso antes de fazer algo. (Bruna, 21 anos)

[Aprendi] Principalmente as lições que a Lore traz. A Lore de Mists of Pandaria ${ }^{4}$. Como mestre de guilda, aprendi na prática diversas coisas sobre administrar problemas e situações e também liderar um grupo.

Além da incorporação dos mitos, a consciência dos jogadores também pode ser ampliada pelo contato com outros jogadores. Embora os MMORPGs possibilitem uma grande quantidade de disputas internas, eles também demandam trabalho em equipe para que objetivos mais difíceis sejam atingidos. Dos 185 jogadores (58\%) que afirmaram ter aprendido algo com WoW, 23\% deles mencionaram o trabalho em equipe. O percentil é o mais alto entre as respostas, seguido do aprendizado de inglês, com $21 \%$. Os jogadores assinalaram a importância do trabalho em equipe tanto no mundo do jogo como fora dele, seja no âmbito profissional ou pessoal.

Com o world of warcraft comecei a perceber a importância do trabalho em equipes. Comecei a jogar world of warcraft e ao momento que vi que o meu individualismo no jogo não era capaz de me levar a diante, comecei a criar amizades no jogo, me juntar a grupos e lutar juntos por um ideal maior. (Gustavo, 20 anos)

[Aprendi] O princípio de que não importa quão caótica uma situação esteja, através de trabalho em equipe e esforço, tudo pode ser consertado. (Danilo, 23 anos)

\footnotetext{
${ }^{3}$ Os Pandaren são uma raça de heróis que se assemelham a pandas humanóides e são inspirados em filosofias orientais.

${ }^{4}$ Mists of Pandaria é uma expansão do jogo no qual os Pandaren passam a fazer parte do universo de World of Warcraft
} 
Melhor gestão de equipe (raid leader) ${ }^{5}$. Para o meu curso (administração) ser raid leader é papel fundamental para aprender mais sobre liderança e comportamento da equipe sob pressão (lutas difíceis) (Marcelo, 22 anos)

Menções sobre a importância da colaboração frequentemente as acompanhavam as respostas dos jogadores, assim como a importância do respeito aos outros. A palavra "respeito" é a terceira mais citada (12\%) nas respostas sobre aprendizados com o jogo. Palavras como "paciência" e "ajuda ao próximo" também foram relativamente frequentes.

\begin{abstract}
Você geralmente aprende a lidar com todo o tipo de pessoas, ter paciência com situações, aprende a dividir, e muitas coisas. Afinal, temos pessoas por trás de personagens e nada mais interessante do que colocarmos a vida real em prática lá dentro. (Vitor, 36 anos)

A questão do respeito ser a base de tudo na nossa vida com o próximo, seja ele real, ou virtual.(Aline, 26 anos)

A se imaginar no lugar do outro quando tal tem um problema. (Flávio, 14 anos)

Ensinar, ajudar e sempre ter paciência com quem desconhece alguma coisa porque ninguém nasceu sabendo de tudo e a troca de conhecimento e experiências é que ajudam a sociedade evoluir como um conjunto e não como unidade (Gabriel, 29 anos)
\end{abstract}

Nota-se que o caráter coletivo do jogo leva os jogadores a interagirem entre si, realizando trocas, ajudando-se mutuamente e tendo de organizar-se em função de certos desafios. A experiência, por sua vez, gera mudanças na atitude consciente que permearão não só a persona do jogador enquanto herói e as relações que trava no jogo, mas também aquelas fora dele. Parte desses aprendizados são simétricos a valores morais apregoados por filosofias ou instituições religiosas, como o respeito à alteridade, empatia, cooperação e harmonia. Robert Geraci, pesquisador inglês de religiosidade, ciência e tecnologia, também observa em WoW uma experiência religiosa a partir do momento em que o game coloca o jogador frente aos conflitos entre bem e mal através de seu enredo, o que lhes dá a oportunidade de refletir sobre questões éticas e morais, bem como coloca-las em prática nas interações do jogo (GERACI, 2015).

Além de aprender um pouco das formas morais como a Honra, o Respeito, a justiça, a diversidade, a amizade e companheirismo, aprendi também com a comunicação entre estrangeiros, um pouco a mais de Língua Inglesa. Aprendi a ter uma liderança mais justa, mais correta e mais companheira do que eu já tinha antes, de ser um pouco mais calmo perante as situações diversas de meu dia-a-dia. E com

\footnotetext{
${ }^{5}$ Raids são atividades grupais de exploração e combate contra monstros. As equipes de Raid podem ser compostas de 10 ou 25 jogadores.
} 
alguns aspectos do jogo e história dele, aprendi que as ambições e a vingança não nos levam a nada de fato. (Ricardo, 18 anos)

Existem várias filosofias no jogo que podem sim ser aproveitadas no mundo real. As histórias tentam nos ensinar lições que diversos outros meios também tentam, como as fábulas e a literatura em geral, etc. Além disso, o wow é baseado na cultura que vivenciamos hoje, logo na expansão de Pandária, por exemplo, pude presenciar melhor como é a cultura oriental sem nunca ter ido diretamente lá. (Nicolas, 17 anos)

As respostas à questão que vêm sendo utilizada foram analisadas e reunidas em 45 palavras-chave diferentes que expressam aprendizados múltiplos com o jogo. Mais da metade dessas palavras-chave apresentam frequência de $1 \%$ ou menos. São palavras como "autocontrole", "matemática"; "amadurecimento"; "bondade"; "filosofia" e "herborismo", por exemplo. A princípio, isso demonstra a potencialidade difusa do MMORPG no que diz respeito ao que pode ser depreendido dele pelo jogador. Contudo, essa variabilidade, ao lado dos outros $42 \%$ de jogadores que não afirmaram ter aprendido algo de útil às suas vidas com o jogo, mostram que a experiência com o jogo é bastante variável. Considerados os limites dos dados apresentados, podemos afirmar que para uma parcela dos jogadores de WoW a experiência com o jogo proporcionoulhes uma ampliação de consciência, construída e expressa de formas distintas, variável a cada jogador. Isso significa dizer que embora o MMORPG possa ser visto como o palco de realização de algumas fantasias - gnósticas ou não - há outras dinâmicas psicológicas em processo que podem produzir efeitos de ampliação de consciência nos jogadores.

\section{Considerações Finais}

Como vimos com Smyth (2007) e com o grande número de jogadores de WoW, o RPG Online tem um efeito atrativo sobre aqueles que entram em contato com ele, o que amplia o espectro de experiências possíveis com o jogo. Por serem historicamente recentes, os jogos digitais costumam ser alvo de preconceitos a respeito de sua relevância e dos efeitos benéficos ou maléficos que podem surtir em seus jogadores. Concepções empobrecidas, exageradas ou ingênuas do jogo podem representa-lo como uma distração, um mero escape da realidade ou um tipo de lazer sedentário que nada acrescentaria àqueles engajados nos jogos. 
É preciso superar tais preconceitos e encarar a presença crescente do jogo - e da tecnologia -na vida de crianças, jovens e adultos como um fenômeno ao qual mais atenção e novas pesquisas deverão ser dedicadas, posta sua versatilidade em relação aos efeitos sobre os jogadores. Pesquisadores e entusiastas do tema, como Jane McGonigal, chamam a atenção para a utilidade e potencialidade dos jogos em contextos educacionais, trabalhistas, pessoais e de saúde, e encara-os como passíveis de "incrementar nossas capacidades humanas mais essenciais - sermos felizes, resilientes e criativos - e nos empoderar para mudar o mundo de forma significativa" (MCGONIGAL, 2011, p. 14).

Através da reflexão sobre a mitologia do jogo ou de sua incorporação, os jogadores podem mudar perspectivas de si e do mundo fora ou dentro do jogo, rompendo com posturas ou posicionamentos e, assim, denotando o encontro dos deuses que surge na mudança de perspectiva que Hillman (1988) fez menção. Além disso, no contato com a alteridade e na dependência do outro durante o jogo cria-se um cenário propício para a aprendizagem de respeito, cooperação e empatia, muito embora suas contrapartes também tenham expressão notável no jogo. Também se postula que na criação de um herói-persona e na relação com ele, o jogador possa desenvolver diferentes aspectos de sua personalidade através da forma como se comporta no jogo e interage com seus pares.

Embora efeitos a médio e longo prazo do jogo, especialmente os do gênero RPG, careçam de mais estudos e pesquisas, vemos que eles podem assumir um caráter sagrado em si mesmos, ao romper com um quotidiano desencantado, além de reaproximar os sujeitos de narrativas e vivências míticas. Contudo, deve-se ter cuidado para que o jogo não seja transformado em uma fantasiosa força onipotente. O equívoco é tentador, pois o ciberespaço e os objetos que a ele se ligam assumem a forma de deuses no imaginário contemporâneo.

A tecnognose e suas fantasias tendem apenas a se intensificar nos próximos anos se considerarmos o ritmo de surgimento de novas tecnologias e sua crescente incorporação na vida cotidiana. Em especial, chama-se a atenção para os dispositivos de realidade virtual que chegarão em breve ao mercado, como o Oculus Rift. Dispensando os televisores, a experiência com jogos assume contornos ainda mais intrigantes, uma vez que a sensação de desmaterialização do corpo e transposição da consciência para a 
cena do jogo serão muito mais intensos. Sem dúvida, não é apenas nos jogos que a realidade virtual terá seu espaço.

Devemos estar cientes das fantasias e imagens atuais que circulam ao redor da tecnologia para que suas expressões futuras não nos sejam tão desconhecidas. Embora uma tecno-religiosidade já esteja em plena expressão, é importante que não se perca de vista a pluralidade dos fenômenos. Mesmo que envolta em ideologia, religiosidade ou fantasias, a tecnologia de fato guarda potenciais múltiplos que se expressarão muitas vezes paralelos a uma inflação de seu poder e papel na vida humana. Como objetos ricos de significados, expressões e potências, tecnologia e jogos podem percorrer as vias do religioso ao mais profano e do inócuo ao benéfico ou prejudicial, passando pelo contato com variadas fantasias e medos. Ganha pontos extras quem trata-los em sua pluralidade.

\section{Referências:}

ABREU, C. N. D. et al. Dependência de Internet e de jogos eletrônicos: uma revisão. Revista Brasileira de Psiquiatria, 2008. 156-167.

CASTELLA, T. D. Have Jedi created a new 'religion'? BBC NEWS, 25 Outubro 2014. Disponivel em: <http://www.bbc.com/news/magazine-29753530>.

COLLMAN, A. The real church of Jediism - THOUSANDS believe in religion based off the Star Wars franchise. Daily Mail, 17 Outubro 2013. Disponivel em: <http://www.dailymail.co.uk/news/article-2465445/Jediism-THOUSANDS-believereligion-based-Star-Wars-franchise.html> .

DAVIS, K. C. Don't know much about mythlogy. New York: HarperCollins Publishers, 2006.

ELÍADE, M. O sagrado e o profano. São Paulo: Martins Fontes, 1992.

FELINTO, E. Tecnognose: tecnologias do virtual, identidade e imaginação espiritual. Revista FAMECOS, 2002. 15-26.

FELINTO, E. A tecnoreligião e o sujeito pneumático no imaginário da cibercultura. Logos, 21, n. 2, 2004. 12-31.

G1. Em 10 anos, 'World of Warcraft' registra 100 milhões de jogadores. G1 Games, 28 Janeiro 2014. Disponivel em:

<http://g1.globo.com/tecnologia/games/noticia/2014/01/em-10-anos-world-warcraftregistra-100-milhoes-de-jogadores.html>. 
GERACI, R. M. Virtually Sacred: Myth and Meaning in World of Warcraft and Second Life. American Journal of Play, 2015. 262-264.

HILlMAN, J. Psicologia Arquetípica. São Paulo: Editora Cultrix, 1988.

HOPCKE, R. H. Guia para a Obra Completa de C. G. Jung. Petrópolis, RJ: Vozes, 2011.

HUIZINGA, J. Homo Ludens. [S.1.]: Editora Perspectiva, 2000.

KOYRÉ, A. Galileu e Platão. Do mundo do "mais ou menos" ao universo da precisão. Lisboa: Gradiva, 1986.

LEMOS, A. Cibercultura: tecnologia e vida social na cultura contemporânea. $2^{\mathrm{a}}$. ed. Porto Alegre: Editora Sulina, 2004.

LÉVY, P. O que é o virtual? 2a . ed. Rio de Janeiro: Editora 34, 2011.

MAFFESOLI, M. A contemplação do mundo. São Paulo: Artes Ofícios, 1995.

MAFFESOLI, M. O tempo das tribos. Rio de Janeiro: Editora Forense Universitária, 2006.

MCGONIGAL, J. Reality is broken: Why games make us better and how they can change the world. Nova York: The Penguin Press, 2011.

SIQUEIRA, D. D. C. O. A ciência na televisão: mito, ritual e espetáculo. São Paulo: Annablume, 1999.

SMYTH, J. M. Beyond self-selection in video game play: an experimental examination of the consequences of massively multiplayer online role-playing game play.

Cyberpsychology and behavior, v. 10, p. 717-721, 2007.

STATISTA. Number of World of Warcraft subscribers from 1st quarter 2005 to 1st quarter 2015 (in millions). Statista - The Statistes Portal, 29 Maio 2015. Disponivel em: <http://www.statista.com/statistics/276601/number-of-world-of-warcraftsubscribers-by-quarter/>.

SUBLETTE, V. A.; MULLAN, B. Consequences of Play: A Systematic Review of the Effects of Online Gaming. International Journal of Mental Health and Addiction, 10, n. 1, 2012. 3-23.

TEMPLE OF THE JEDI ORDER. Doctrine of the Order. Temple of the Jedi Order, s.d. Disponivel em: <http://www.templeofthejediorder.org/doctrine-of-the-order>. Acesso em: 26 Maio 2015.

WEBER, M. A ética protestante e o "espírito" do capitalismo. São Paulo: Companhia das letras, 1920/2004.

WORLD OF WARCRAFT. Classes. Battle Net, 5 Maio 2015. Disponivel em: <http://us.battle.net/wow/pt/game/class/>. 
YOUTUBE. Michel Maffesoli - O Reencantamento do mundo. Disponível em: <https://www.youtube.com/watch?v=lcuKuXLyZNU>. Acesso em 12 de Maio de 2015.

Recebido: 21/06/2015

Received: 06/21/2015

Aprovado: 13/07/2015

Approved: 07/13/2015 